\title{
EFFECT OF B-BLOCKERS ON THE RISK OF ATRIAL FIBRILLATION IN PATIENTS WITH ACUTE MYOCARDIAL INFARCTION
}

\author{
Antonio Eduardo Pesaro, Alexandre de Matos Soeiro, Carlos Vicente Serrano, \\ Roberto Rocha Giraldez, Renata Teixeira Ladeira, José Carlos Nicolau
}

doi: 10.1590/S1807-59322010000300005

Pesaro AE, Soeiro AM, Serrano CV, Giraldez RR, Ladeira RT, Nicolau JC. Effect of $\beta$-blockers on the risk of atrial fibrillation in patients with acute myocardial infarction. Clinics. 2010;65(3):265-70.

INTRODUCTION: Oral $\beta$-blockers improve the prognosis of patients with acute myocardial infarction, while atrial fibrillation worsens the prognosis of this population. The reduction of atrial fibrillation incidence in patients treated with $\beta$-blockers could at least in part explain the benefits of this drug.

OBJECTIVE: To investigate the effect of $\beta$-blockers on the incidence of atrial fibrillation in patients with acute myocardial infarction. METHODS: We analyzed 1401 patients with acute myocardial infarction and evaluated the occurrence or absence of atrial fibrillation, the use of oral $\beta$-blockers and mortality during the first 24 hours.

RESULTS: a) The use of $\beta$-blockers was inversely correlated with the presence of atrial fibrillation $(\rho=0.004$; OR $=0.54$ ). b) Correlations with mortality were as follows: $31.5 \%$ in patients with atrial fibrillation, $9.2 \%$ in those without atrial fibrillation $(\rho<0.001$; Odds Ratio $=4.52)$, and $17.5 \%$ in patients not treated with $\beta$-blockers and $6.7 \%$ in those who received the drug $(\rho<0.001$; OR $=0.34)$. c) Adjusted Models: The presence of atrial fibrillation was independently correlated with mortality $(\mathrm{OR}=2.48, \rho=0.002)$. The use of $\beta$-blockers was inversely and independently correlated with mortality $(\mathrm{OR}=0.53 ; \rho=0.002)$. The patients who used $\beta$-blockers showed a lower risk of atrial fibrillation $(\mathrm{OR}=0.59 ; \rho=0.029)$ in the adjusted model.

CONCLUSION: The presence of atrial fibrillation and the absence of oral $\beta$-blockers increased in-hospital mortality in patients with acute myocardial infarction. Oral $\beta$-blockers reduced the incidence of atrial fibrillation, which might be at least partially responsible for the drug's benefit.

KEYWORDS: Acute myocardial infarction; $\beta$-blockers; Atrial fibrillation; Mortality; Arrhythmias.

\section{INTRODUCTION}

In the United States, more than one million people suffer an acute myocardial infarction (AMI) each year. Even with recent advances in diagnosis and treatment, global mortality rates are still around $30 \% .{ }^{1}$ Several studies have shown that the early use of $\beta$-blockers in patients with AMI is able to limit the extent of myocardial injury and improve the shortand long-term prognosis. ${ }^{1-9}$ Thus, routine use of $\beta$-blockers is recommended in patients with AMI, provided there are no

Heart Institute (InCor HCFMUSP), Acute Coronary Care Unit, Hospital das Clínicas da Faculdade de Medicina da Universidade de São Paulo - São Paulo/SP, Brazil.

Email: alexandre.soeiro@bol.com.br

Tel.: 55113069.5058

Received for publication on November 26, 2009

Accepted for publication on December 07, 2009 contraindications.

It has classically been accepted that the main mechanisms responsible for the beneficial effects of $\beta$-blockers involve blocking myocardial sympathetic stimulation, a decrease in heart rate and blood pressure and a benefit for heart remodeling. ${ }^{1}$ However, some recent publications have suggested that the reduction in the incidence of arrhythmias after AMI, seen after $\beta$-blocker treatment, could also have a leading role in explaining the benefits obtained with the use of these drugs. ${ }^{2,11-17}$ It is also well demonstrated that atrial fibrillation $(\mathrm{AF})$ is considered a factor of poor prognosis in myocardial infarction, even in adjusted models. ${ }^{14,18-25}$

In this context, we analyzed data from 1401 patients with AMI in a single institution in order to investigate the effect of $\beta$-blockers on the incidence of $\mathrm{AF}$ and to analyze the relationships between mortality in 24 hours and 1) the use of $\beta$-blockers and 2) the incidence of AF. 


\section{METHODS}

This study was a retrospective unicentric study. All included patients with AMI $(\mathrm{n}=1401$; median age $=63$ years) were hospitalized in a single coronary intensive care unit and were prospectively included in a specific database. The patients were analyzed during the first 24 hours after hospitalization. The definitions and medical procedures followed the institutional routines, in accordance with recent guidelines. During this period, AF was treated with synchronized electrical cardioversion and the use of amiodarone in all patients.

A diagnosis of AMI was established when patients had chest pain at rest with concomitant ischemic ST-T changes and positive serum troponin. ${ }^{26}$ The left ventricular ejection fraction (LVEF) was calculated by Doppler echocardiography (Simpson). Only the period when patients were hospitalized was analyzed, taking into account the presence of AF, the use of oral $\beta$-blockers and all-cause mortality. Categorical variables were compared using Pearson's chi-square test or Fisher's exact test, as indicated. The Student's t test was used to compare continuous variables.

In adjusted models, the analyses were performed by stepwise logistic regression. In the first model, AF was included as a dependent variable. The adjusted $\mathrm{R}^{2}$ was 0.114. The following variables were considered independent: LVEF, age, gender, previous diabetes mellitus, previous myocardial infarction, current myocardial infarction location, ST elevation, admission creatinine, coronary surgery and angioplasty during hospitalization, use of aspirin, angiotensin-converting enzyme inhibitor and use of $\beta$-blockers. In the second model, death was the dependent variable. AF was added to the other independent variables included in the first model. The adjusted $\mathrm{R}^{2}$ of this model was 0.226 .

In all models, statistical significance was set at 5\% $(\rho<$ $0.05)$.

\section{RESULTS}

\section{a. Population studied}

As stated above, 1401 patients were examined. The average age of the population was $63.19+12.7$ years and 1021 patients $(72.9 \%)$ were men. The left ventricular ejection fraction was, on average, $51.1 \%+15.5$. During the hospitalization, 150 patients $(10.7 \%)$ died.

\section{b. Univariate analysis}

\section{b.1. Occurrence of $A F$}

The baseline characters and univariate analysis of their association with AF is shown in Table 1 . The use of $\beta$-blockers was inversely correlated with the presence of AF. As shown in Table 1, age, diabetes mellitus, previous AMI, coronary surgery, angioplasty, creatinine clearance and LVEF also had a significant correlation with the presence of AF. Excluding patients who used intravenous $\beta$-blockers followed by oral $\beta$-blockers did not change the results; the $\rho$ value was 0.009 for the correlation between oral $\beta$-blockers and AF.

Table 1 - Baseline characters in patients with AF and without AF

\begin{tabular}{|c|c|c|c|c|}
\hline Variables & $\mathrm{AF}(\mathrm{n}=92)$ & Without AF $(\mathrm{n}=1309)$ & Odds Ratio & $\rho$ value * \\
\hline Age (years) & $70+/-10.3$ & $63+/-12.8$ & & $<0.001$ \\
\hline Male gender $(\%)$ & 65.2 & 73.4 & 2.92 & NS \\
\hline Diabetes mellitus (\%) & 38 & 27.3 & 1.64 & 0.026 \\
\hline Previous AMI (\%) & 41.3 & 27 & 1.91 & 0.003 \\
\hline CABG $(\%)$ & 34.8 & 17.1 & 2.58 & $<0.0001$ \\
\hline PTCA $(\%)$ & 26.1 & 36.8 & 0.61 & 0.038 \\
\hline $\operatorname{LVEF}(\%)$ & $0.43+/-16.4$ & $0.51+/-15.3$ & & $<0.001$ \\
\hline Creatinine clearance & $38.3+/-20.4$ & $55.7+/-41.5$ & & $<0.001$ \\
\hline STEMI (\%) & 55.4 & 57.2 & 0.93 & NS \\
\hline Anterior AMI (\%) & 43.5 & 42.8 & 1.03 & NS \\
\hline$\beta$-Blocker (\%) & 48.9 & 63.8 & 0.54 & 0.004 \\
\hline ACE inhibitors (\%) & 54.3 & 50 & 1.19 & NS \\
\hline Aspirin (\%) & 94.6 & 94.3 & 1.06 & NS \\
\hline
\end{tabular}

$\mathrm{AF}=$ atrial fibrillation; $\mathrm{AMI}=$ acute myocardial infarction; $\mathrm{CABG}=$ coronary artery bypass grafting; PTCA = percutaneous coronary angioplasty; LVEF $=$ left ventricular ejection fraction; STEMI = ST elevation myocardial infarction; ACE = angiotensin-converting enzyme inhibitor; NS = not significant. $*=\rho<0.05$. 


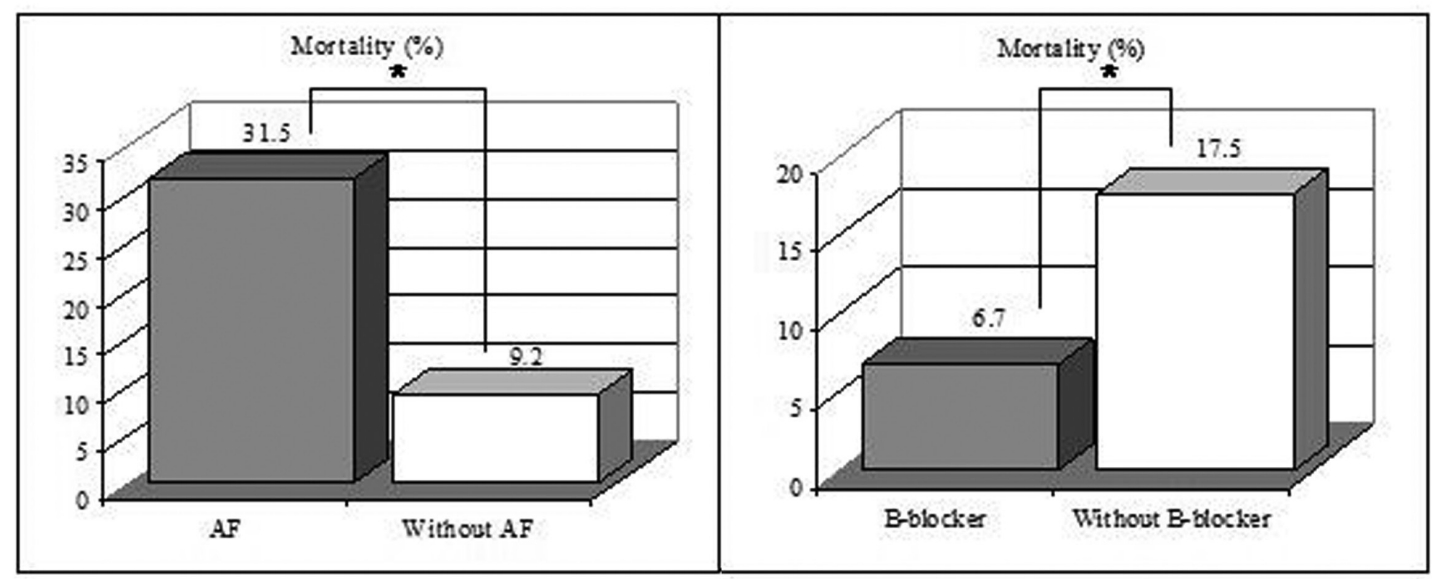

Figure 1 - The relationship between use of $\beta$-Blocker and $\mathrm{AF}$ with mortality. Legend: $\mathrm{AF}=$ atrial fibrilation. $*=\rho<0.001$.

\section{b.2. Mortality}

As noted in Figure 1,31.5\% of the patients in the group that presented with AF died, compared to $9.2 \%$ in the group without arrhythmia $(\rho<0.001$; Odds Ratio $=4.52)$. Figure 1 clearly shows an inverse correlation between the use of $\beta$-blockers and mortality $(17.5 \%$ mortality in patients who did not use $\beta$-blockers and $6.7 \%$ mortality in those that did; $\rho<0.001$; OR $=0.34$ ). LVEF and age also showed a correlation with mortality (Table 2). The incidence of death among women was $13.2 \%(50 / 380)$, while in males it was $9.8 \%(100 / 1021, \mathrm{OR}=0.72, \rho=0.07)$. Two hundred and forty patients used both oral and intravenous $\beta$-blockers. The results did not change when these patients were excluded. Values of $\rho<0.001$ were found for the correlations between mortality and the use of oral $\beta$-blockers, AF, and also found between use of oral $\beta$-blockers or presence of AF and mortality.

Table 2 - The relationship between age, ejection fraction and mortality LVEF = left ventricle ejection fraction

\begin{tabular}{lcc}
\hline & Age (years)* & Ejection fraction of LVEF* \\
\hline Deaths & $72+/-11.9^{\#}$ & $0.41+/-15.0^{\#}$ \\
Live & $62+/-12.4^{\#}$ & $0.52+/-15.1^{\#}$ \\
\hline
\end{tabular}

$*$ = average; + - standard deviation; ${ }^{*}=\rho$ value $<0.001$.

\section{c. Adjusted Models}

\section{c.1. Occurrence of $A F$}

The patients who used $\beta$-blockers showed a lower risk of $\mathrm{AF}(\mathrm{OR}=0.59 ; \rho=0.029)$ in the adjusted model. Age, coronary surgery and LVEF also had a significant correlation with the presence of AF, as shown in Table 3.

\section{c.2. Mortality}

The multivariate analysis of the association between
Table 3 - Multivariate analysis of the association between different clinical variables and the occurrence of $\mathrm{AF}$

\begin{tabular}{lccc}
\hline Variables & Odds Ratio & CI 95\% & $\rho$ value* \\
\hline Age & 1.045 & $1.024-1.067$ & $<0.0001$ \\
Diabetes mellitus & 1.164 & $0.711-1.907$ & NS \\
Previous AMI & 1.297 & $0.792-2.124$ & NS \\
CABG & 3.085 & $1.886-5.057$ & $<0.0001$ \\
PTCA & 0.925 & $0.531-1.611$ & NS \\
LVEF & 0.968 & $0.952-0.983$ & $<0.001$ \\
Creatinine clearance & 1.248 & $0.960-1.621$ & NS \\
STEMI & 1.144 & $0.703-1.861$ & NS \\
Anterior AMI & 1.008 & $0.621-1.634$ & NS \\
$\beta$-Blocker & 0.59 & $0.367-0.948$ & 0.029 \\
ACE inhibitors & 1.492 & $0.925-2.408$ & NS \\
Aspirin & 0.9 & $0.328-2.471$ & NS \\
\hline AF & &
\end{tabular}

$\mathrm{AF}=$ atrial fibrillation $\mathrm{CI}=$ confidence interval $; \mathrm{AMI}=$ acute myocardial infarction; $\mathrm{CABG}=$ coronary artery bypass grafting; $\mathrm{PTCA}=$ percutaneous coronary angioplasty; $\mathrm{LVEF}=$ left ventricular ejection fraction; STEMI = ST elevation myocardial infarction; $\mathrm{ACE}=$ angiotensin-converting enzyme inhibitor; NS $=$ not significant. $*=\rho<0.05$.

different clinical variables and mortality is shown in Table 4. The presence of AF was independently correlated with mortality $(\mathrm{OR}=2.48, \rho=0.002)$. The use of $\beta$-blockers was inversely and independently correlated with mortality $(\mathrm{OR}=$ $0.52 ; \rho=0.002$ ). Table 4 also shows the correlation between mortality and age, LVEF, creatinine clearance and use of angiotensin-converting enzyme inhibitors.

\section{Limitations}

This study was a retrospective study based on a databank. However, the fact that the data were included prospectively decreases the chance of any bias related to the results. Due to retrospective design of the study, 
Table 4 - Multivariate analysis of the association between different clinical variables and mortality

\begin{tabular}{lccc}
\hline Variables & Odds Ratio & CI 95\% & $\rho$ value* \\
\hline Age & 1.061 & $1.042-1.081$ & $<0.0001$ \\
Diabetes mellitus & 1.097 & $0.703-1.712$ & $\mathrm{NS}$ \\
AF & 2.476 & $1.399-4.382$ & 0.002 \\
Previous AMI & 0.781 & $0.495-1.233$ & $\mathrm{NS}$ \\
CABG & 1.222 & $0.720-2.075$ & $\mathrm{NS}$ \\
PTCA & 0.703 & $0.436-1.133$ & $\mathrm{NS}$ \\
LVEF & 0.955 & $0.940-0.969$ & $<0.001$ \\
Creatinine clearance & 1.694 & $1.297-2.214$ & $<0.001$ \\
STEMI & 1.127 & $0.732-1.737$ & $\mathrm{NS}$ \\
Anterior AMI & 1.089 & $0.709-1.671$ & $\mathrm{NS}$ \\
$\beta$-Blocker & 0.521 & $0.342-0.794$ & 0.002 \\
ACE inhibitors & 0.481 & $0.312-0.740$ & 0.001 \\
Aspirin & 1.027 & $0.451-2.337$ & $\mathrm{NS}$ \\
\hline
\end{tabular}

$\mathrm{AF}=$ atrial fibrillation $\mathrm{CI}=$ confidence interval $\mathrm{AMI}=$ acute myocardial infarction; $\mathrm{CABG}=$ coronary artery bypass grafting; $\mathrm{PTCA}=$ percutaneous coronary angioplasty; $\mathrm{LVEF}=$ left ventricular ejection fraction; $\mathrm{STEMI}=$ ST elevation myocardial infarction; $\mathrm{ACE}=$ angiotensin-converting enzyme inhibitor; NS $=$ not significant. $*=\rho<0.05$.

some important data, including echocardiography parameters (ejection fraction, left atrial size, left ventricular hypertrophy, diastolic function), electrolyte levels and oxygen status are missing.

\section{DISCUSSION}

In accordance with previous evidence, this sample showed a significant association between the use of $\beta$-blockers and reduction in mortality during the hospitalization of patients with AMI. In these results, the lack of $\beta$-blocker use was related to increased mortality and AF. This correlation remained significant even in adjusted models. Most studies that evaluated the effect of $\beta$-blockers after AMI reported a short-term reduction of up to $50 \%$ in the risk of death, similar to our results. . $^{1,3,5,6,8}$ However, there are no studies that clearly associated $\beta$-blockers, AF and inhospital mortality after an AMI.

Dargie et al. conducted a randomized, multicenter, placebo-controlled study (CAPRICORN) examining the use of carvedilol in 1959 infarcted patients with left ventricular dysfunction $(\mathrm{EF}<40 \%)$ over a period of 1.3 years. As expected, the observed mortality was lower in the group that received carvedilol than in the control group (12\% vs. $15 \%$, respectively, $\rho=0.03) .{ }^{9}$ Recently, the COMMIT/ CCS-2 study ${ }^{10,27}$ assessed the in-hospital use of intravenous metoprolol followed by oral treatment in 45,852 patients with ST-segment elevation AMI. Despite the reduction in ventricular arrhythmias in the $\beta$-blocker group, the drug was related to an increased risk of cardiogenic shock, especially in patients in Killip 3 and 4. These results raised some issues: should $\beta$-blockers be used orally or intravenously? Which mechanisms are responsible for the drug's benefit? In what group of patients should we use the drug after AMI? In fact, a previous study, based on the GUSTO- 1 trial, showed a larger benefit in patients who used oral $\beta$-blockers than in those who used intravenous followed by oral treatment. ${ }^{12}$ In our study, intravenous $\beta$-blockers was not better than oral treatment. In any case, all of the available evidence has led the most recent guidelines to suggest caution when using intravenous $\beta$-blockers after AMI. ${ }^{26}$

The analysis of AF after AMI showed that, as in previous publications, patients who had had an arrhythmia during hospitalization had an increased mortality rate ( $31 \%$ vs. $9.2 \%, \rho<0.001) .^{14,15,18-25}$ Laurent et al. conducted a retrospective study in patients with non-ST elevation AMI. The study showed that the occurrence of AF in the first 24 hours after AMI significantly increased inhospital mortality compared to patients who did not have the arrhythmia (21\% vs. $6 \%$, respectively, $\rho=0.03) .{ }^{21} \mathrm{In}$ another retrospective study, Pedersen et al. observed that patients with left ventricular dysfunction who had AF after AMI also showed increased in-hospital mortality (OR = $1.8, \rho<0.05) .{ }^{20}$ In a sub-analysis of the GUSTO-III trial, 13,858 patients were assessed after AMI. Investigators correlated the occurrence of AF and prognosis. The mortality in patients with AF was greater than in the group without the arrhythmia $[\mathrm{OR}=1.63(1.31-2.02)] .{ }^{28}$ Additionally, Asanin et al. demonstrated that the recurrence of AF during hospitalization for AMI further increases the risk of death compared to those with a single episode of arrhythmia (36.1\% vs. $12.9 \%$, respectively). ${ }^{14}$

Regarding the anti-arrhythmic effects of $\beta$-blockers, previous studies have shown controversial results regarding the ability of the drug to reduce the risk of AF after AMI. ${ }^{13,14,18,28,29}$ A study conducted by McCullough et al. prospectively examined the benefits of the use of $\beta$-blockers in 1724 patients after AMI with chronic renal failure. The authors reported a significant reduction in the incidence of $\mathrm{AF}$ in patients using $\beta$-blockers compared to patients who had not used the drug $(9.5 \%$ vs. $16.4 \%$, respectively, $\mathrm{p}<0.0001) .{ }^{13}$ On the other hand, other major studies have found different results. The retrospective analysis of the AIRE study, which assessed the use of $\beta$-blockers in patients with AMI and ventricular dysfunction, showed reduced mortality but no differences in the incidence of arrhythmia in patients who used the drug. ${ }^{18}$ Similarly, Yilmaz et al. reported an AF incidence of $23.8 \%$ after AMI, without any reduction in the risk of 
arrhythmia in the group treated with $\beta$-blockers. ${ }^{29}$ On the other hand, our study found a significant increase in the incidence of $\mathrm{AF}$ in patients who had not used $\beta$-blockers compared to those who used the drug. Even after multivariate analysis, the risk of AF in patients who had not used $\beta$-blockers remained high and significant.

\section{CONCLUSION}

The presence of $\mathrm{AF}$ and the absence of oral $\beta$-blocker use increased in-hospital mortality in patients with AMI. Oral $\beta$-blockers reduced the incidence of $\mathrm{AF}$, a mechanism that might be at least partially responsible for the drug's benefit.

\section{REFERENCES}

1. Kopecky SL. Effect of beta blockers, particularly carvedilol, on reducing the risk of events after acute myocardial infarction. Am J Cardiol. 2006;98:1115-9.

2. Stenestrand U, Lindback J, Wallentin L, RIKS-HIA Registry. Anticoagulation therapy in atrial fibrillation in combination with acute myocardial infarction influences long-term outcome: a prospective cohort study from the Register of Information and Knowledge About Swedish Heart Intensive Care Admissions (RIKS-HIA). Circulation. 2005;112:3225-31.

3. Herlitz J, Waagstein F, Lindqvist J, Swedberg K, Hjalmarson A. Effect of metoprolol on the prognosis for patients with suspected acute myocardial infarction and indirect signs of congestive heart failure (a subgroup analysis of the Goteborg Metoprolol Trial). Am J Cardiol. 1997;80(9B):40J-44J.

4. Pitt B, Fonarow GC, Gheorghiade M, Deedwania PC, Duprez DA. Improving outcomes in post-acute myocardial infarction heart failure: incorporation of aldosterone blockade into combination therapy to optimize neurohormonal blockade. Am J Cardiol.;97(10A):26F-33F.

5. Berger AK, Duval S, Krumholz HM. Aspirin, beta-blocker, and angiotensin-converting enzyme inhibitor therapy in patients with end-stage renal disease and an acute myocardial infarction. J Am Coll Cardiol.;42:201-8.

6. Anzai T, Yoshikawa T, Takahashi T, Maekawa Y, Okabe T, Asakura Y, et al. Early use of beta-blockers is associated with attenuation of serum C-reactive protein elevation and favorable short-term prognosis after acute myocardial infarction. Cardiology. 2003;99:47-53.

7. Hognestad A, Dickstein K, Myhre E, Snapinn S, Kjekshus J; OPTIMAAL Investigators. Effect of combined statin and beta-blocker treatment on one-year morbidity and mortality after acute myocardial infarction associated with heart failure. Am J Cardiol. 2004;93:603-6.

8. Weir R, McMurray JJ. Treatments that improve outcome in the patient with heart failure, left ventricular systolic dysfunction, or both after acute myocardial infarction. Heart. 2005;91 Suppl 2:ii17-20; discussion ii31, ii43-8.

9. Dargie HJ. Effect of carvedilol on outcome after myocardial infarction in patients with left-ventricular dysfunction: the CAPRICORN randomised trial. Lancet. 2001;357:1385-90.

10. III Diretriz sobre tratamento do infarto agudo do miocárdio. Arq Bras Cardiol. 2004 (83) Suplemento IV.

11. Garton M. COMMIT/CCS-2 studies. Lancet. 200619;368:642.

12. Goodman SG, Langer A, Ross AM, Wildermann NM, Barbagelata A, Sgarbossa EB, et al. Non-Q-wave versus Q-wave myocardial infarction after thrombolytic therapy: angiographic and prognostic insights from the global utilization of streptokinase and tissue plasminogen activator for occluded coronary arteries-I angiographic substudy. GUSTO-I Angiographic Investigators. 1998;97:444-50.

13. McCullough PA, Sandberg KR, Borzak S, Hudson MP, Garg M, Manley HJ. Benefits of aspirin and beta-blockade after myocardial infarction in patients with chronic kidney disease. Am Heart J. 2002;144:226-32.

14. Asanin M, Perunicic J, Mrdovic I, Matic M, Vujisic-Tesic B, Arandjelovic A, et al. Significance of recurrences of new atrial fibrillation in acute myocardial infarction. Int J Cardiol. 200610;109:235-40.

15. Kober L, Swedberg K, McMurray JJ, Pfeffer MA, Velazquez EJ, Diaz $\mathrm{R}$, et al. Previously known and newly diagnosed atrial fibrillation: a major risk indicator after a myocardial infarction complicated by heart failure or left ventricular dysfunction. Eur J Heart Fail. 2006;8:591-8.

16. Wong CK, White HD, Wilcox RG, Criger DA, Califf RM, Topol EJ, et al. Management and outcome of patients with atrial fibrillation during acute myocardial infarction: the GUSTO-III experience. Global use of strategies to open occluded coronary arteries. Heart. 2002;88:357-62.

17. McMurray J, Køber L, Robertson M, Dargie H, Colucci W, LopezSendon J, et al. Antiarrhythmic effect of carvedilol after acute myocardial infarction: results of the Carvedilol Post-Infarct Survival Control in Left Ventricular Dysfunction (CAPRICORN) trial. J Am Coll Cardiol. 200515;45:525-30

18. Spargias KS, Hall AS, Greenwood DC, Ball SG. Beta blocker treatment and other prognostic variables in patients with clinical evidence of heart failure after acute myocardial infarction: evidence from the AIRE study. Heart. 1999;81:25-32.

19. Sakata K, Kurihara H, Iwamori K, Maki A, Yoshino H, Yanagisawa A, Ishikawa K. Clinical and prognostic significance of atrial fibrillation in acute myocardial infarction. Am J Cardiol. 1997;80:1522-7.

20. Pedersen OD, Bagger H, Kober L, Torp-Pedersen C; FACC, on behalf of the TRACE Study Group. Impact of congestive heart failure and left ventricular systolic function on the prognostic significance of atrial fibrillation and atrial flutter following acute myocardial infarction. Int J Cardiol. 20058;100:65-71.

21. Laurent G, Zeller M, Dentan G, Moreau D, Laurent Y, Beer JC, et al. Prognostic impact of new onset atrial fibrillation in acute non-ST elevation myocardial infarction data from the RICO survey. Heart. 200;91:369-70.

22. Rathore SS, Berger AK, Weinfurt KP, Schulman KA, Oetgen WJ, Gersh $\mathrm{BJ}$, et al. Acute myocardial infarction complicated by atrial fibrillation in the elderly: prevalence and outcomes. Circulation. 2007;101:969-74.

23. Serrano CV Jr, Ramires JA, Mansur AP, Pileggi F. Importance of the time of onset of supraventricular tachyarrhythmias on prognosis of patients with acute myocardial infarction. Clin Cardiol. 1995;18:84-90. 
24. Petrina M, Goodman SG, Eagle KA. The 12-lead electrocardiogram as a predictive tool of mortality after acute myocardial infarction: current status in an era of revascularization and reperfusion. Am Heart J. 2006; 152:11-8.

25. Asanin M, Perunicic J, Mrdovic I, Matic M, Vujisic-Tesic B, Arandjelovic A, et al. Prognostic significance of new atrial fibrillation and its relation to heart failure following acute myocardial infarction. Eur J Heart Fail. 2005;7:671-6.

26. Canadian Cardiovascular Society, American Academy of Family Physicians, American College of Cardiology, American Heart Association, Antman EM, Hand M, et al. 2007 focused update of the ACC/AHA 2004 guidelines for the management of patients with ST-elevation myocardial infarction: a report of the American College of Cardiology/American Heart Association Task Force on Practice Guidelines. J Am Coll Cardiol. 2008;51:210-47.
27. Chen ZM, Pan HC, Chen YP, Peto R, Collins R, Jiang LX, et al. Early intravenous then oral metoprolol in 45,852 patients with acute myocardial infarction: randomised placebo-controlled trial. Lancet. 20055;366:1622-32.

28. Wong CK, White HD, Wilcox RG, Criger DA, Califf RM, Topol EJ, et al. New atrial fibrillation after acute myocardial infarction independently predicts death: the GUSTO-III experience. Am Heart J. 2000;140:87885

29. Yilmaz R, Kasap H, Baykan M, Durmus I, Kaplan S, Celik $\mathrm{S}$, et al. Assessment of left ventricular function by Doppler tissue imaging in patients with atrial fibrillation following acute myocardial infarction. Int J Cardiol. 2005;102:79-85. 